\title{
Interspecific and nutrient-dependent variations in stable isotope fractionation: experimental studies simulating pelagic multitrophic systems
}

\author{
N. Aberle · A. M. Malzahn
}

Received: 23 November 2006/Accepted: 5 July 2007

(C) Springer-Verlag 2007

\begin{abstract}
Stable isotope signatures of primary producers display high inter- and intraspecific variation. This is assigned to species-specific differences in isotope fractionation and variable abiotic conditions, e.g., temperature, and nutrient and light availability. As consumers reflect the isotopic signature of their food source, such variations have direct impacts on the ecological interpretation of stable isotope data. To elucidate the variability of isotope fractionation at the primary producer level and the transfer of the signal through food webs, we used a standardised marine tritrophic system in which the primary producers were manipulated while the two consumer levels were kept constant. These manipulations were (1) different algal species grown under identical conditions to address interspecific variability and (2) a single algal species cultivated under different nutrient regimes to address nutrient-dependent variability. Our experiments resulted in strong interspecific variation between different algal species (Thalassiosira weissflogii, Dunaliella salina, and Rhodomonas salina) and nutrient-dependent shifts in stable isotope signatures in response to nutrient limitation of $R$. salina. The trophic enrichment in ${ }^{15} \mathrm{~N}$ and ${ }^{13} \mathrm{C}$ of primary and secondary consumers (nauplii of Acartia tonsa and larval herring) showed strong deviations from the postulated degree of $1.0 \%$ enrichment in $\delta^{13} \mathrm{C}$ and $3.4 \%$ enrichment in $\delta^{15} \mathrm{~N}$.
\end{abstract}

Communicated by Jörg Ganzhorn.

N. Aberle

IFM-GEOMAR Leibniz Institute of Marine Sciences,

Kiel, Germany

N. Aberle $(\bowtie) \cdot$ A. M. Malzahn

Biologische Anstalt Helgoland,

Stiftung Alfred-Wegener Institute

for Polar and Marine Research, Helgoland, Germany
Surprisingly, nauplii of $A$. tonsa tended to keep "isotopic homeostasis" in terms of $\delta^{15} \mathrm{~N}$, a pattern not described in the literature so far. Our results suggest that the diets' nutritional composition and food quality as well as the stoichiometric needs of consumers significantly affect the degree of trophic enrichment and that these mechanisms must be considered in ecological studies, especially when lower trophic levels, where variability is highest, are concerned.

Keywords Food quality · Homeostasis . Clupea harengus . Trophic interactions .

Food-web studies

\section{Introduction}

Stable isotopes have been considered a major tool in ecology for decades, and the use of natural ratios of the stable carbon $\left({ }^{13} \mathrm{C} /{ }^{12} \mathrm{C}\right)$ and nitrogen $\left({ }^{15} \mathrm{~N} /{ }^{14} \mathrm{~N}\right)$ isotopes for the reconstruction of food sources and trophic interactions have gained considerable importance in terrestrial and aquatic environments (Peterson and Fry 1987; Ponsard and Arditi 2000). Due to a stepwise enrichment of heavier isotopes from one trophic level to the next, natural isotope ratios can be used to trace consumer diets and to gain a better understanding of food-web interactions (Vander Zanden and Rasmussen 2001; Post 2002). This stepwise enrichment is assumed to be about $1.0 \%$ for $\delta^{13} \mathrm{C}$ and $3.4 \%$ for $\delta^{15} \mathrm{~N}$ between trophic levels (Minangawa and Wada 1984; Peterson and Fry 1987). However, this assumption has been criticised, arguing that it disregards the variation in trophic fractionation, especially at lower trophic levels (Vander Zanden and Rasmussen 2001).

To date, it is known that the degree of enrichment can vary between species and, furthermore, that within species, 
the environmental, physiological and nutritional conditions can alter the isotopic compositions of primary producers (Fry 1996; Burckhardt et al. 1999; Needoba et al. 2003). Although there is an increasing knowledge of fractionation processes in autotrophs and indication that the actual degree of trophic enrichment in consumers can exceed by far the postulated degree of enrichment (Macko et al. 1983), the transfer of these signals to higher trophic levels has been the subject of only a few experimental studies (Schlechtriem et al. 2004; Haubert et al. 2005; Tamelander et al. 2006). Variation in trophic enrichment is assumed to be related to variations in stable isotope composition of food sources, metabolic processes (Ponsard and Averbuch 1999; Gorokhova and Hansson 1999), inter- and intraspecific differences (Vander Zanden and Rasmussen 2001; Post 2002), the $\mathrm{C} / \mathrm{N}$ ratio of the food source as well as food availability (Adams and Sterner 2000; Vanderklift and Ponsard 2003). However, there is still a lot of debate in stable isotope ecology concerning the forcing factors of enrichment processes.

The present study aimed to elucidate the variability of isotope fractionation at the primary producer level and to trace enrichment processes through a tri-trophic food chain by experimental investigations on (1) interspecific variations of stable isotope signatures between different algal species, (2) nutrient-dependent variations of algae in relation to nutrient regimes and (3) the transfer of the primary producers' signal to primary (copepods) and secondary (larval herring) consumers.

\section{Materials and methods}

Algal cultures and growth

Stock culture of the diatom Thalassiosira weissfogii, the green alga Dunaliella salina and the cryptophyte Rhodomonas salina were cultivated in $\mathrm{f} / 2$ media following Guillard and Ryther (1962). For the experimental trials, we cultivated algae at $17^{\circ} \mathrm{C}$ under a light/dark cycle of $16 / 8 \mathrm{~h}$ in enriched natural seawater amended with nutrients at different levels (for nutrient details, see description in the section on "Interspecific $1+2$ " and "Limitation $1+2$ "). The entire water used for cultivation during the experiments was taken from the Baltic Sea at the beginning of February to guarantee winter nutrient concentrations. Subsequently, the water was $0.2-\mu \mathrm{m}$ sterile filtered and stored cold and dark until use.

Prior to the experiments, a cell number versus in vivo fluorescence relationship was set up for each alga culture using flow cytometry. This calibration was used in the following for the daily determination of algal concentrations using in vivo fluorescence measurements (Turner,
10-AU-005-CE) at an excitation wavelength of $436 \mathrm{~nm}$ and an emission wavelength of $680 \mathrm{~nm}$. Algae cultures were ventilated with an aeration system to ensure a sufficient $\mathrm{CO}_{2}$ supply.

\section{Acartia tonsa cultures}

Prior to the experiments, eggs of the calanoid copepod Acartia tonsa were produced in 200-1 cylindrical tanks. Copepods were cultivated at $18^{\circ} \mathrm{C}$ at a $12 / 12$ light cycle. Copepods were fed on a mixture of the algae $R$. salina and D. salina and the flagellate Oxhyrris spec. Eggs were siphoned from the bottom of the tanks daily and stored in seawater at $4{ }^{\circ} \mathrm{C}$ for later use. No eggs older than 3 months were used in the experiments. Hatch rate was around $20 \%$.

\section{Fish-larvae cultures}

Larval herring were obtained by means of artificial fertilisation. Female fish were strip spawned on glass plates. Eggs were incubated in a flow-through system using $4 \mu \mathrm{m}$ prefiltered natural seawater at $13^{\circ} \mathrm{C}$. Larvae hatched after 11 days and were transferred to cylindrical 200-1 stock tanks. The stock tanks were operated as a flow-trough system and supplied with prefiltered water. The egg incubation and the hatching procedures were conducted twice with a time gap of 10 days in-between in order to use larvae from the first trial for Interspecific 1 and Limitation 1 and the second trial for Interspecific 2 and Limitation 2.

Interspecific experiments

Algae

Cultures of $T$. weissflogii, D. salina and $R$. salina were cultivated in natural seawater amended with nutrients to final concentrations of $30 \mu \mathrm{mol} 1^{-1}$ nitrogen, $2 \mu \mathrm{mol} 1^{-1}$ phosphorous and, in case of the diatom $T$. weissflogii $80 \mu \mathrm{mol} 1^{-1}$ silicate. To ensure constant food qualities and quantities, new cultures of each algal species were inoculated every day, and the amount of cells at the beginning was kept constant for each species $\left(250\right.$ cells $\mathrm{ml}^{-1}$ for $R$. salina, 400 cells $\mathrm{ml}^{-1}$ for $D$. salina and 3 cells $\mathrm{ml}^{-1}$ for $T$. weissflogii). The different amounts inoculated were in relation to the different biovolumes of the algae $\left(383 \mu \mathrm{m}^{3}\right.$ for $R$. salina, $24 \mu^{3}$ for D. salina and $3,192 \mu \mathrm{m}^{3}$ for $T$. weissflogii) to keep the biovolumes for each algae species constant. The cultures were harvested at mean densities of 360,000, 880,000 and 47,000 cells $\mathrm{ml}^{-1}$ (R. salina, D. salina and $T$. weissflogii, respectively) after 7 days. These 
were the maximum attainable densities during the predefined exponential growth phase under the given light and nutrient regimes. Isotope composition of each algal batch culture at the end of the growth period was measured. For each experimental run (Interspecific $1+2$ ) the batch-tobatch variation of algae isotope composition was calculated from the mean value $[ \pm$ standard deviation $(\mathrm{SD})]$ of all batch cultures (13-15 batches per treatment) used as food sources for primary consumers over the duration of the entire experimental period.

\section{Consumers}

The copepods used for the experiments were reared in filtered seawater from the egg to the fifth naupliar stage at densities of 1,500 ind. $1^{-1}$ in 5-1 plastic bags at $17^{\circ} \mathrm{C}$. Copepods were fed first $48 \mathrm{~h}$ after adding the eggs to the rearing bags, assuming 2 days for the development from the egg to the first-feeding second naupliar stage. Copepods were harvested after 7 days of cultivation reaching the fifth naupliar stage. Isotope composition of each copepod culture was measured at the end of the feeding period; cultureto-culture variation $( \pm \mathrm{SD})$ was calculated from the mean of all copepod cultures harvested during the experiments (9-11 batches per treatment). Three new copepod bags were started at each day of the feeding experiment to ensure a constant food quality for herring larvae as secondary consumers. Interspecific 1 was started using 3-days' posthatch herring larvae, which had no feeding experience. The rest of the larvae in the stock tanks were fed on Brachionus plicatilis from day 4. Interspecific 2 was started using 7 days post hatch larvae.

Two hundred herring larvae each were transferred to 201 tanks filled with GF/F filtered seawater. For each treatment, one herring larvae tank was used. Larvae were fed daily around midday with copepods reared with the three different algal diets. Approximately $50 \%$ of the water was replaced daily. Water was changed before feeding to ensure that the majority of prey organisms remained in the experimental containers for a maximum of $24 \mathrm{~h}$. This was essential to avoid alterations of body composition and a change in isotope signatures of the copepods due to starvation and hence to assure constant food quality over the trial period. Isotope composition of individual or pooled larvae (one to four larvae per sample) was measured at the end of the feeding period; larvae-to-larvae variation was calculated as the mean $( \pm \mathrm{SD})$ of larvae samples harvested at the end of the experiments (three to ten samples per treatment). For more details on the experimental set-up of the Interspecific experiments, see Tables 1 and 2.

Limitation experiments

Algae

The cryptophyte $R$. salina was cultivated in enriched seawater, under phosphorous limitation and under nitrogen limitation. The first treatment simulated a nonlimited bloom situation and consisted of $\mathrm{f} / 2$-enriched seawater ( $\mathrm{f} / 2$ in the following), as described by Guillard and Ryther (1962); the other two treatments simulated decaying bloom situations under $\mathrm{N}$ or $\mathrm{P}$ limitation. The algae of the two limitation treatments were enriched with just one macronutrient (no $\mathrm{P}$ or $\mathrm{N}$ addition; - $\mathrm{P}$ and $-\mathrm{N}$ in the following) and could therefore only utilise the natural $\mathrm{P}$ or $\mathrm{N}$ sources contained in the seawater at the moment of filtration.

To ensure constant food quality, new cultures of each of the treatments were inoculated every day with roughly $0.2 \times 10^{6}$ cells ml $^{-1}$ for the $-\mathrm{N}$ treatment and 0.3 for the $-\mathrm{P}$ and $f / 2$ treatments. Algae were harvested at densities of approximately $0.5,1.0$, and $1.3 \times 10^{6}$ cells $\mathrm{ml}^{-1}(-\mathrm{N},-\mathrm{P}$ and $f / 2$, respectively) after the predefined growth phase of 6 days for $-\mathrm{N}$ and 7 days for $\mathrm{f} / 2$ and $-\mathrm{P}$. These were the maximum densities possible to culture with the natural $\mathrm{N}$ or P sources contained in the seawater. For all treatments, algae were fed to the primary consumers at a concentration of $1.0-\mathrm{mg}$ carbon per litre copepod culture medium $\mathrm{d}^{-1}$. Concurrent with the Interspecific experiments, samples for isotope composition of algae batch cultures were sampled at the end of the growth period. For each experimental run

Table 1 Experimental details of the Interspecific and the Limitation experiments

\begin{tabular}{|c|c|c|c|c|c|c|}
\hline $\begin{array}{l}\text { Experimental } \\
\text { run }\end{array}$ & $\begin{array}{l}\text { Temperature } \\
\left({ }^{\circ} \mathrm{C}\right)\end{array}$ & $\begin{array}{l}\text { Age of herring } \\
\text { larvae }\left(\mathrm{d}^{-1}\right) \\
\text { at start }\end{array}$ & $\begin{array}{l}\text { Copepod diet } \\
(\mathrm{mg} \text { algal } \\
\left.\text { carbon } \mathrm{l}^{-1} \mathrm{~d}^{-1}\right)\end{array}$ & $\begin{array}{l}\text { Herring larvae } \\
\text { diet }\left(\text { copepods } 1^{-1}\right)\end{array}$ & $\begin{array}{l}\text { Days of } \\
\text { copepod feeding }\end{array}$ & $\begin{array}{l}\text { Days of herring } \\
\text { larvae feeding }\end{array}$ \\
\hline Interspecific 1 & 17 & 3 & 1.0 & 1 & 5 & 5 and 8 \\
\hline Interspecific 2 & 17 & 7 & 1.0 & 1 & 5 & 5 and 8 \\
\hline Limitation 1 & 15 & 4 & 1.0 & 1 & 5 & 5 \\
\hline Limitation 2 & 15 & 9 & 1.0 & 1 & 5 & 5 \\
\hline
\end{tabular}




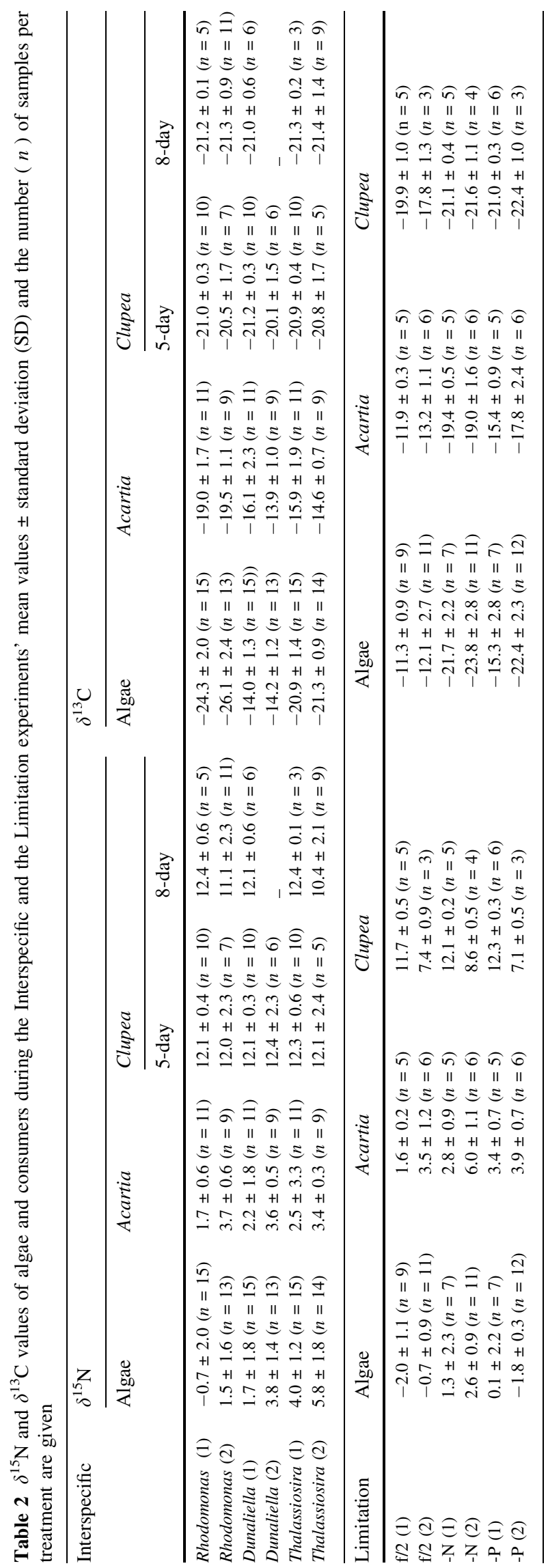

(Limitation $1+2$ ), the batch-to-batch variation of algae isotope composition was calculated from the mean value ( \pm SD) of all batch cultures (7-12 batches per treatment).

\section{Consumers}

The copepods used for the Limitation experiments were reared in the same way as for the Interspecific experiments. In order to guarantee the algal mineral limitation in the copepod rearing bags also, copepods were reared in artificial, $\mathrm{N}$ - and P-free seawater (hw-Marinemix, http://www.hw-wiegandt.de). Again, the first feeding of the second naupliar stages of the copepods started $48 \mathrm{~h}$ after adding the eggs to the incubation chambers. Similar to the Interspecific experiments, three new copepod bags were started each day, copepod cultures were measured at the end of the feeding period and culture-to-culture variation ( \pm SD) was calculated (five to six batches per treatment).

Limitation 1 was started using 4 days' posthatch larvae, which had no feeding experience. The rest of the larvae in the stock tanks were fed on $B$. plicatilis from day 4 . Limitation 2 was started using 9 days' posthatch larvae.

Twenty larvae each were transferred to 1-1 glass beakers filled with $\mathrm{GF} / \mathrm{F}$ filtered seawater. The three treatments $(-\mathrm{P},-\mathrm{N}, \mathrm{f} / 2)$ were replicated 10 times in Limitation 1 and three times in Limitation 2. More than $80 \%$ of the water was replaced daily. Water was changed before feeding to ensure that the vast majority of uneaten prey organisms were in the experimental container for a maximum of $24 \mathrm{~h}$ to avoid alterations of the body composition of the copepods due to starvation. Isotope composition of single or pooled larvae (1-4 larvae per sample) was measured at the end of the feeding period; larvae-to-larvae variation is given as the mean ( \pm SD) of larvae at the end of the experiments (three to six samples per treatment). For more details on the experimental set-up of the Limitation experiments see Tables 1 and 2.

Stable isotope analysis and fractionation

According to cell densities, the amount of each alga species needed for stable isotope analysis was calculated, and the biovolume of the amount of algae sampled each day was kept constant. Thereafter, the algae were filtered on precombusted GF/F filters. For stable isotope analysis of $A$. tonsa, a total of 1,000 nauplii was sampled each day; and for herring larvae, several individuals of newly hatched larvae were pooled (two to three individuals per sample). For the 3-10 days' posthatch larvae, individual larvae were measured. Samples for stable isotope analysis of 
algae, copepod nauplii and herring larvae were all transferred to tin caps (HEKAtech) and dried in an oven at $50^{\circ} \mathrm{C}$.

Stable isotope analysis of the samples was performed by using an isotope ratio mass spectrometer (Thermofinnigan EA 1110 CHNS). During measurements, the mass spectrometer determines the ratio of stable isotope ${ }^{13} \mathrm{C} /{ }^{12} \mathrm{C}$ and ${ }^{15} \mathrm{~N} /{ }^{14} \mathrm{~N}$. Isotopic compositions are expressed by the $\delta$ notation, which are parts per thousand deviations from a standard.

$\delta X=\left(R_{\text {sample }} / R_{\text {standard }}-1\right) \times 1000$

$R=\quad$ heavy/light isotope

$\delta X>0=$ enriched in heavy isotope

$\delta X<0=$ depleted in heavy isotope or enriched in light isotope

An acetanilide standard with $\delta^{15} \mathrm{~N}$ of $-2.56 \% \pm 0.53$ (SD) and $\delta^{13} \mathrm{C}$ of $-30.45 \% \pm 0.79(\mathrm{SD})$ was measured after every sixth samples during mass spectrometry. Trophic fractionation of stable isotopes is described in terms of the difference in delta $(\delta)$ values between food source $(\mathrm{A})$ and consumer $(\mathrm{B})$ using the $\Delta$ notation, where $\Delta=\delta_{\mathrm{B}}-\delta_{\mathrm{A}}$. A positive $\Delta$ value indicates a relatively greater concentration of the heavier isotope in B. Food source isotope composition was calculated as the average of algal diets' isotope composition of batch cultures over the experimental period and the copepods' isotope composition at the day of sampling. To account for variability in isotope signatures between A. tonsa cultures, mean isotope fractionation per culture and SDs are given. Isotope composition of $A$. tonsa as food source for herring larvae was calculated as the average of $A$. tonsa signatures during the course of the feeding period of larvae; mean isotope fractionation per larvae and SD are given to account for variability between larvae.

\section{Statistical analysis}

To test for significant differences in $\delta^{15} \mathrm{~N}$ and $\delta^{13} \mathrm{C}$ values of algae and consumers during the Interspecific and the Limitation experiments, two-factorial analysis of variance (ANOVA) with the independent factors experiment run (F1) and food source (F2) and a Tukey's HSD test were performed using STATISTICA. Relationships between diet stoichiometry and trophic fractionation as well as between diet-stable isotope signatures and trophic fractionation are based on linear regressions between the mean $\mathrm{C}: \mathrm{N}, \delta^{15} \mathrm{~N}$, $\Delta \delta^{15} \mathrm{~N}, \delta^{13} \mathrm{C}, \Delta \delta^{13} \mathrm{C}$ value calculated for every treatment. To test the significance of the linear regressions, GraphPad Prism (GraphPad Software Inc.) was used.

\section{Results}

Interspecific experiments

\section{Isotope composition of algae}

During the experiments, the $\delta^{15} \mathrm{~N}$ showed significant variations between the different algae and between Interspecific 1 and 2 (for $P$ values, see Table 3 ). The $\delta^{15} \mathrm{~N}$ values ranged from $-0.7 \%$ $\pm 2.0-4.0 \% \pm \pm 1.2$ (Interspecific 1 ) to $1.5 \% \pm 1.6-5.8 \% \pm 1.8$ (Interspecific 2 ) for $R$. salina and T. weissflogii, respectively (Fig. 1a) (values give

Table $3 \delta^{15} \mathrm{~N}$ and $\delta^{13} \mathrm{C}$ values of algae and consumers during the Interspecific and the Limitation experiments

\begin{tabular}{|c|c|c|c|c|c|c|c|}
\hline \multirow[t]{3}{*}{$\delta^{15} \mathrm{~N}$} & \multicolumn{4}{|c|}{ Interspecific } & \multicolumn{3}{|c|}{ Limitation } \\
\hline & \multirow[t]{2}{*}{ Algae } & \multirow[t]{2}{*}{ Acartia } & \multicolumn{2}{|l|}{ Clupea } & \multirow[t]{2}{*}{ Algae } & \multirow[t]{2}{*}{ Acartia } & \multirow[t]{2}{*}{ Clupea } \\
\hline & & & 5-day & 8-day & & & \\
\hline Experiment run & 0.000 & 0.001 & 0.935 & - & 0.959 & 0.000 & 0.000 \\
\hline Food source & 0.000 & 0.094 & 0.941 & 0.355 & 0.000 & 0.000 & 0.004 \\
\hline Experiment run $\times$ food source & 0.779 & 0.506 & 0.854 & - & 0.064 & 0.007 & 0.004 \\
\hline \multirow[t]{2}{*}{$\delta^{13} \mathrm{C}$} & \multirow[t]{2}{*}{ Algae } & \multirow[t]{2}{*}{ Acartia } & \multicolumn{2}{|c|}{ Clupea } & \multirow[t]{2}{*}{ Algae } & \multirow[t]{2}{*}{ Acartia } & \multirow[t]{2}{*}{ Clupea } \\
\hline & & & 5-day & 8-day & & & \\
\hline Experiment run & 0.0337 & 0.020 & 0.074 & - & 0.019 & 0.034 & 0.887 \\
\hline Food source & 0.0000 & 0.000 & 0.720 & 0.866 & 0.000 & 0.000 & 0.000 \\
\hline Experiment run $\times$ food source & 0.1423 & 0.034 & 0.459 & - & 0.028 & 0.067 & 0.001 \\
\hline
\end{tabular}

$P$ values of the two-factorial analysis of variance (ANOVA) with the independent factors experiment run (F1) and food source (F2) and $\delta^{15} \mathrm{~N}$ and $\delta^{13} \mathrm{C}$ as dependent variables. Eight-day-old herring from the Interspecific experiment were analysed by a one-factorial ANOVA using food source as the independent variable 
Fig. $1 \delta^{15} \mathrm{~N}(\mathbf{a}), \delta^{13} \mathrm{C}(\mathbf{b})$, $\Delta \delta^{15} \mathrm{~N}(\mathbf{c})$ and $\Delta \delta^{13} \mathrm{C}(\mathbf{d})$ of algae, Acartia and Clupea [mean \pm standard deviation (SD)] after $5(5 d)$ and 8 days ( $8 d)$ of feeding during the first (1) and the second (2) Interspecific experiment. The diet basis was: Rho (Rhodomonas salina), Dun (Dunaliella salina), Thal (Thalassiosira weissflogii). Dashed lines indicate the postulated degree of $3.4 \%$ enrichment in $\delta^{15} \mathrm{~N}$ (c) and $1.0 \%$ enrichment in $\delta^{13} \mathrm{C}$ and (d)
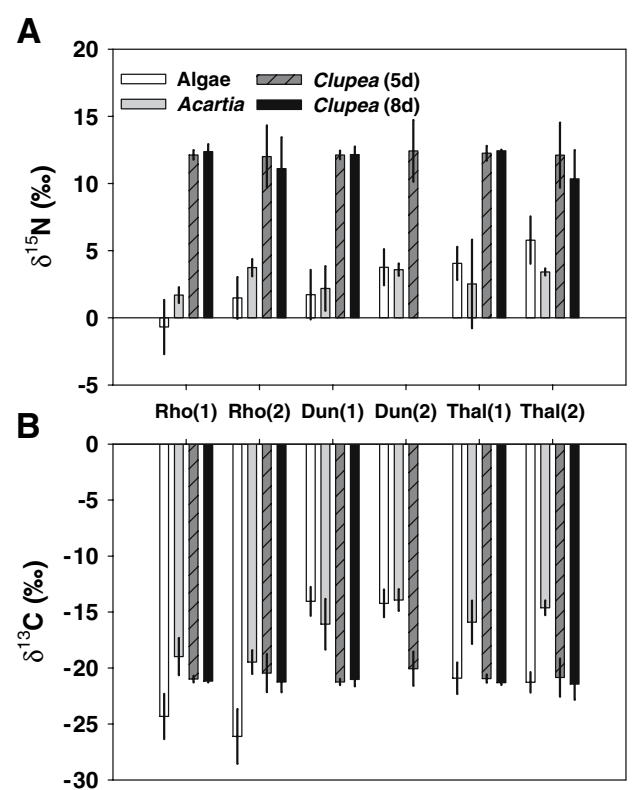

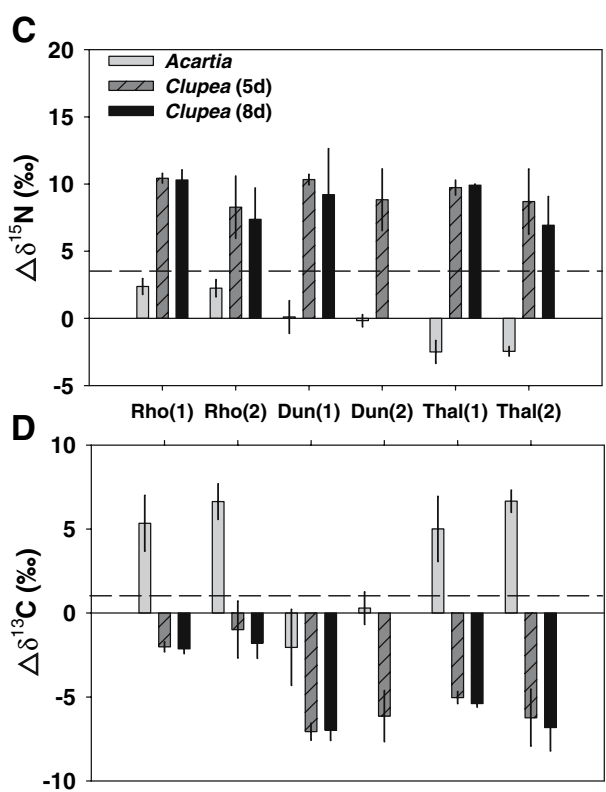

the mean per treatments and \pm 1 SD). Different algal species showed significant variations in their $\delta^{13} \mathrm{C}$ values between the experimental runs, ranging from $-14.0 \% \pm$ 1.3 to $-24.3 \%$ \pm 2.0 (Interspecific 1 ) and $-14.2 \% \pm \pm 1.2$ to $-26.1 \% \pm 2.4$ (Interspecific 2) for $D$. salina and $R$. salina, respectively (Fig. 1b).

\section{Isotope composition of consumers}

During Interspecific 1 , the $\delta^{15} \mathrm{~N}$ values of $A$. tonsa nauplii ranged from $1.7 \%$ o 1.7 ( $R$. salina diet) to $2.5 \%$ s $\pm 3.3(T$. weissflogii diet) (Fig. 1a), but no significant variations could be observed depending on the food source. During Interspecific 2, the $\delta^{15} \mathrm{~N}$ values of nauplii were in mean $1-$ $2 \%$ higher than during the first experiment, and the differences between experimental runs were significant. $\delta^{15} \mathrm{~N}$ ranged from $3.4 \%$ o \pm .3 on $T$. weissflogii diet to $3.7 \%$ \% 0.6 on $R$. salina diet. In terms of $\delta^{13} \mathrm{C}$, nauplii showed significant variations between treatments and in the $D$. salina and $T$. weissflogii treatments also between the experimental runs. The $\delta^{13} \mathrm{C}$ values differed significantly, ranging from $-15.9 \% \pm 1.9$ (T. weissflogii diet) to $-19.0 \% \pm 1.7$ (R. salina diet) during Interspecific 1 and $-13.9 \% \pm 1.0$ (D. salina diet) to $-19.5 \% \pm 1.1$ ( $R$. salina diet) during Interspecific 2 (Fig. 1b).

The initial $\delta^{15} \mathrm{~N}$ of herring yolk-sac larvae right after hatch (start) was similar during both experiments, with values of $12.6 \% \pm 0.3$ (Interspecific 1 ) and $11.8 \% \pm 1.7$ (Interspecific 2). In terms of $\delta^{13} \mathrm{C}$, the values between both experiments showed a $1 \%$ difference, with values of $-22.4 \%$ \pm 0.3 (Interspecific 1 ) and $-21.4 \%$ \pm 1.3 (Interspecific 2).
After 5 days of feeding, herring larvae showed only slight changes in the $\delta^{15} \mathrm{~N}$ and $\delta^{13} \mathrm{C}$ when compared with the initial values of the yolk-sac larvae. After 5 days of feeding, $\delta^{15} \mathrm{~N}$ of larvae showed no significant differences in relation to food sources and experimental runs with values ranging from $12.0 \% \pm 2.3$ (Rho; Interspecific 2) to $12.4 \%$ \pm 2.3 (Dun; Interspecific 2) (Fig. 1a). $\delta^{13} \mathrm{C}$ ranged from $-20.1 \% \pm 1.5$ (Dun; Interspecific 2) to $-21.2 \% \pm 0.3$ (Dun; Interspecific 1) and no significant differences between food sources and experimental runs were observed (Fig. 1b). This pattern changed only slightly after 8 days of feeding during Interspecific 2, where changes in $\delta^{15} \mathrm{~N}$ of larvae fed on $R$. salina- and $T$. weissflogii-based diet were about 1-2\% depleted compared with larvae after 5 days of feeding. However, the differences were not significant (Fig. 1a).

\section{Trophic fractionation}

The enrichment of stable isotope signatures per trophic level showed a high variability, and no constant patterns could be observed. Significant variation in the $\Delta \delta^{15} \mathrm{~N}$ of $A$. tonsa nauplii was observed between food sources but not between experimental runs (for $P$ values, see Table 4). Nauplii fed with $R$. salina showed $\Delta \delta^{15} \mathrm{~N}$ of $2.3 \% \pm 0.6$ (Interspecific 1) and 2.2\%o \pm 0.6 (Interspecific 2) (Fig. 1c) and thus corresponded most to the empirical degree of enrichment of 3.4\%o. When D. salina or T. weissflogii were the basis of the tri-trophic food chain, hardly any trophic enrichment-and in most cases, a depletion-was observed. Herring larvae as secondary consumers showed a much higher degree of enrichment than the $3.4 \%$ empirical 
Table $4 \Delta \delta^{15} \mathrm{~N}$ and $\Delta \delta^{13} \mathrm{C}$ values of consumers during the Interspecific and Limitation experiments

\begin{tabular}{|c|c|c|c|c|c|}
\hline \multirow[t]{3}{*}{$\Delta \delta^{15} \mathrm{~N}$} & \multicolumn{3}{|c|}{ Interspecific } & \multicolumn{2}{|c|}{ Limitation } \\
\hline & \multirow[t]{2}{*}{ Acartia } & \multicolumn{2}{|c|}{ Clupea } & \multirow[t]{2}{*}{ Acartia } & \multirow[t]{2}{*}{ Clupea } \\
\hline & & 5-day & 8-day & & \\
\hline Experiment run & 0.194 & 0.000 & - & 0.000 & 0.000 \\
\hline Food source & 0.000 & 0.779 & 0.065 & 0.000 & 0.000 \\
\hline Experiment run $\times$ food source & 0.749 & 0.565 & - & 0.061 & 0.130 \\
\hline \multirow[t]{2}{*}{$\Delta \delta^{13} \mathrm{C}$} & \multirow[t]{2}{*}{ Acartia } & \multicolumn{2}{|c|}{ Clupea } & \multirow[t]{2}{*}{ Acartia } & \multirow[t]{2}{*}{ Clupea } \\
\hline & & 5-day & 8-day & & \\
\hline Experiment run & 0.000 & 0.416 & - & 0.000 & 0.003 \\
\hline Food source & 0.000 & 0.000 & 0.000 & 0.000 & 0.000 \\
\hline Experiment run $\times$ food source & 0.578 & 0.008 & - & 0.001 & 0.000 \\
\hline
\end{tabular}

$P$ values of the two-factorial analysis of variance (ANOVA) with the independent factors experiment run (F1) and food source (F2) and $\Delta \delta^{15} \mathrm{~N}$ and $\Delta \delta^{13} \mathrm{C}$ as dependent variables. Eight-day-old herring from the Interspecific experiment were analysed by a one-factorial ANOVA using food source as the independent variable

degree of ${ }^{15} \mathrm{~N}$ enrichment, and the signals were very similar to the initial signatures of larvae. Significant differences in the $\Delta \delta^{15} \mathrm{~N}$ of herring larvae were only observed between experimental runs after 5 days of feeding.

An even stronger variability in trophic fractionation was observed for the $\Delta \delta^{13} \mathrm{C}$ (Fig. 1d), where an enrichment of $1.0 \%$ could not be observed in any case. Significant variation in the $\Delta \delta^{13} \mathrm{C}$ of $A$. tonsa nauplii was observed both between food sources and experimental runs. The $\Delta \delta^{13} \mathrm{C}$ of A. tonsa nauplii on $R$. salina- and T. weissflogii-based diet showed the highest degree of ${ }^{13} \mathrm{C}$ enrichment of $6.7 \%$ \pm 0.7 (Thal) and 6.6\% \pm 1.1 (Rho) during Interspecific 2. A. tonsa nauplii on D. salina-based diet showed a very low degree of ${ }^{13} \mathrm{C}$ enrichment of $0.3 \% \pm 1.0$ (Interspecific 1) or even a depletion of $-2.0 \% \pm 2.3$ (Interspecific 2). Herring larvae showed a strong depletion in ${ }^{13} \mathrm{C}$, and significant variation in the $\Delta \delta^{13} \mathrm{C}$ of larvae was found after 5 and 8 days of feeding. ${ }^{13} \mathrm{C}$-depletion was highest when $D$. salina or T. weissflogii were the basis of the food chain. Significant differences in the $\Delta \delta^{15} \mathrm{~N}$ of herring larvae were only observed between experimental runs.

\section{Limitation experiments}

\section{Isotope composition of algae}

The $\delta^{15} \mathrm{~N}$ of $R$. salina grown under different nutrient regimes showed significant variations. $\delta^{15} \mathrm{~N}$ ranged from $-2.0 \% \pm \pm 1.1(\mathrm{f} / 2)$ to $1.3 \% \mathrm{~m} \pm 2.3(-\mathrm{N})$ during Limitation 1 and $-1.8 \%$ $\pm 0.3(-\mathrm{P})$ to $2.6 \% \pm 0.9(-\mathrm{N})$ during Limitation 2 (Fig. 2a; for $P$ values, see Table 3). The $\delta^{13} \mathrm{C}$ values between the different nutrient treatments showed significant variations in relation to the nutrient status, and the experimental runs ranging from $-21.7 \%$ o $\pm 2.2(-\mathrm{N})$ to $-11.3 \% \pm 0.9 \quad(\mathrm{f} / 2)$ during Limitation 1 and $-23.8 \% \pm 2.8(-\mathrm{N})$ to $-12.1 \% 0 \pm 2.7(\mathrm{f} / 2)$ during Limitation 2 (Fig. 2b).

\section{Isotope composition of consumers}

The $\delta^{15} \mathrm{~N}$ values of $A$. tonsa nauplii showed significant differences in the $\delta^{15} \mathrm{~N}$ in relation to the growth conditions of their algal diets and between experimental runs (Fig. 2a; for $P$ values, see Table 3). During Limitation 1, the $\delta^{15} \mathrm{~N}$ of nauplii ranged from $1.6 \% \pm 0.2(\mathrm{f} / 2$ diets $)$ to $3.4 \%$ \pm 0.7 (-P diets). During Limitation 2, the $\delta^{15} \mathrm{~N}$ ranged from $3.5 \% 0 \pm 1.2$ (f/2 diets) to $6.0 \% 0 \pm 1.1$ (-N diets). In terms of $\delta^{13} \mathrm{C}$, the nauplii showed significant variations between the different nutrient treatments and between Limitations 1 and 2. $\delta^{13} \mathrm{C}$ values ranged from $-11.9 \% \pm \pm 0.3$ (f/2 diets) to $-19.4 \% \pm 0.5 \quad(-\mathrm{N}$ diets) (Limitation 1) and $-13.2 \% \pm 1.1$ (f/2 diets) to $-19.0 \% \pm 1.6$ (-N diets) (Limitation 2) (Fig. 2b). The initial $\delta^{15} \mathrm{~N}$ of herring yolksac larvae right after hatch (start) was the same as during Interspecific 1 and Interspecific 2, as larvae from the same trials were used for the experiments.

After 5 days of feeding, larvae showed only slight changes in $\delta^{15} \mathrm{~N}$ and $\delta^{13} \mathrm{C}$ when compared with the initial values of the yolk-sac larvae (Limitation 1). Their $\delta^{15} \mathrm{~N}$ 
Fig. $2 \delta^{15} \mathrm{~N}(\mathbf{a}), \delta^{13} \mathrm{C}(\mathbf{b})$, $\Delta \delta^{15} \mathrm{~N}(\mathbf{c})$ and $\Delta \delta^{13} \mathrm{C}(\mathbf{d})$ of algae, Acartia and Clupea [mean \pm standard deviation (SD)] during the first ( 1 ) and the second (2) Limitation experiment. Diet basis was Rhodomonas salina grown under different nutrient regimes: $f / 2$ (enriched seawater), $-N$ (nitrogen limited), $-P$ (phosphorous limited). Dashed lines indicate the postulated degree of $3.4 \%$ enrichment in $\delta^{15} \mathrm{~N}(\mathbf{c})$ and $1.0 \%$ enrichment in $\delta^{13} \mathrm{C}(\mathbf{d})$
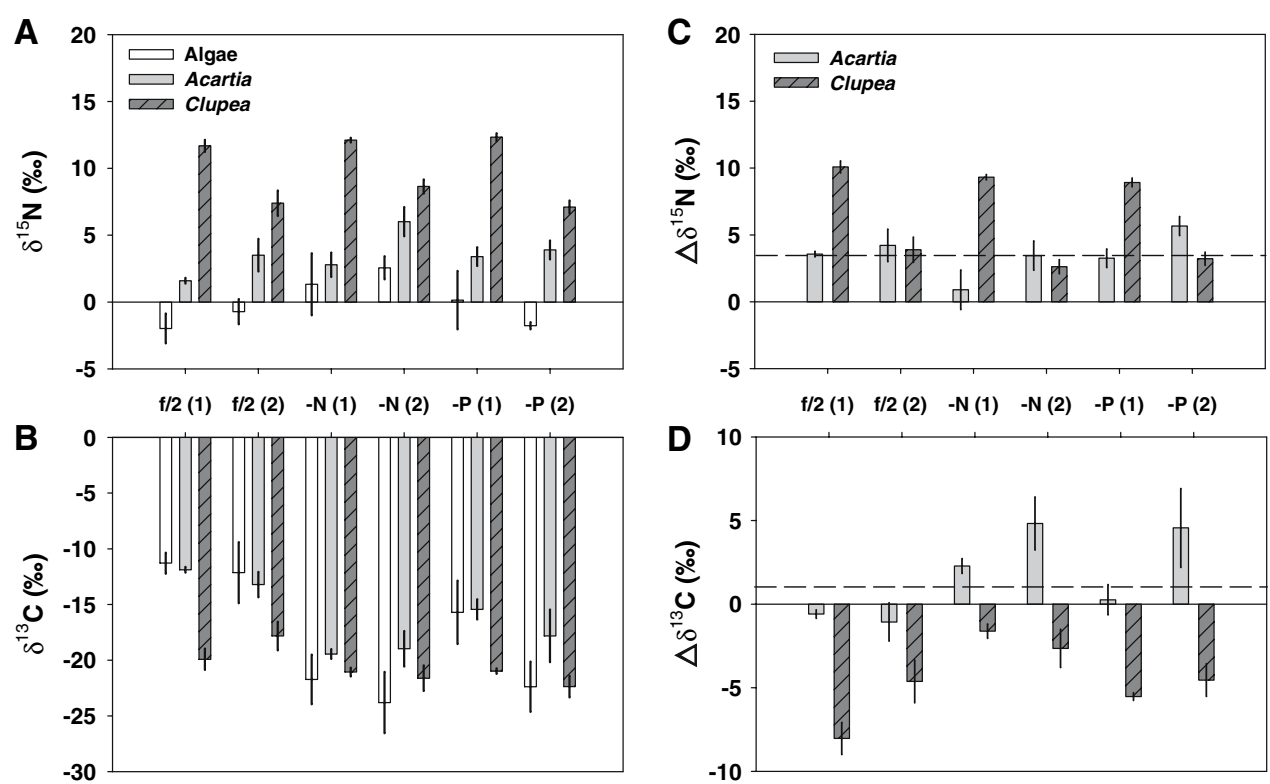

varied significantly between food sources and experimental runs and ranged from $11.7 \%$ o \pm 0.5 ( $\mathrm{f} / 2$ diets) to $12.3 \% \pm 0.3$ (-P diets) (Fig. 2a). During Limitation 2, herring larvae showed depletion in $\delta^{15} \mathrm{~N}$ in comparison with the initial $\delta^{15} \mathrm{~N}$ of yolk-sac larvae ranging from $7.1 \% 0 \pm 0.5$ (-P diets) to $8.6 \% 0 \pm 0.5$ (-N diets). $\delta^{13} \mathrm{C}$ differed significantly between food sources and was slightly higher or lower than the initial $\delta^{13} \mathrm{C}$, ranging from $-19.9 \% \pm 1.0$ (f/2 diets) to $-21.1 \%$ o \pm 0.4 (-N diets) (Limitation 1) and $-17.8 \% \pm 1.3$ (f/2 diets) to $-22.4 \% \pm 1.0$ (-P diets) (Limitation 2, Fig. 2b).

\section{Trophic fractionation}

Some Limitation experiment treatments corresponded well to the empirical degree of $3.4 \%$ enrichment per trophic level. $\Delta \delta^{15} \mathrm{~N}$ of $A$. tonsa nauplii and herring larvae varied significantly between food sources and experimental runs, ranging from $0.9 \% 0 \pm 1.5(-\mathrm{N}$, Limitation 1$)$ to $5.7 \%$ \pm 0.7 (-P, Limitation 2) for A. tonsa (Fig. 2c; for $P$ values, see Table 4) and $2.6 \% \pm 0.5 \quad(-\mathrm{N}, \quad$ Limitation 2$)$ to $10.1 \% \pm 0.5$ (f/2, Limitation 1$)$ for herring larvae. The trophic enrichment of heavier carbon isotopes in A. tonsa nauplii and herring larvae showed a significant variability depending on the food sources and experimental runs and contrasted the empirical degree of enrichment of 1.0\%. In cases where the tri-trophic food chain was based on limited diets (-N and -P diets), the $\Delta \delta^{13} \mathrm{C}$ of nauplii showed a ${ }^{13} \mathrm{C}$ enrichment, whereas on $\mathrm{f} / 2$ diets a depletion was observed (Fig. 2d). $\Delta \delta^{13} \mathrm{C}$ of herring larvae were consistently negative, with the strongest degree of depletion when $R$. salina grown under full media ( $\mathrm{f} / 2)$ and under P-limited conditions were the basis of the food chain.

Diet stoichiometry versus trophic fractionation

During the Interspecific and the Limitation experiments, the relationship between the $\mathrm{C}: \mathrm{N}$ of algae and the $\delta^{15} \mathrm{~N}$ of $A$. tonsa showed no significant relationship (Fig. 3a), whereas there was a negative relation between the $\mathrm{C}: \mathrm{N}$ of the algae and the $\Delta \delta^{15} \mathrm{~N}$ of $A$. tonsa (Fig. $3 \mathrm{~b} ; r^{2}=0.42, P=0.019$ ).

In terms of ${ }^{13} \mathrm{C}$, there was no significant relationship between the $\mathrm{C}: \mathrm{N}$ of algae and the $\delta^{13} \mathrm{C}$ of $A$. tonsa. In contrast, the relationship between $\mathrm{C}: \mathrm{N}$ and $\Delta \delta^{13} \mathrm{C}$ of $A$. tonsa showed a significant positive trend (Fig. 3d; $\left.r^{2}=0.59, P=0.004\right)$.

Diet-stable isotope signatures versus trophic fractionation

When comparing the stable isotope signatures of algae and those of copepod nauplii, no regression was found between $\delta^{15} \mathrm{~N}$ of algae and $\delta^{15} \mathrm{~N}$ of $A$. tonsa (Fig. 4a). In contrast, a negative regression was found between $\delta^{15} \mathrm{~N}$ of algae and $\Delta \delta^{15} \mathrm{~N}$ of $A$. tonsa (Fig. $4 \mathrm{~b} ; r^{2}=0.74, \quad P=0.0002$, $b=-0.92)$.

The relationship between $\delta^{13} \mathrm{C}$ of algae and $\delta^{13} \mathrm{C}$ of $A$. tonsa showed a positive trend (Fig. $4 \mathrm{c} ; r^{2}=0.76$, $P=0.0002, b=0.44$ ), while a significant negative trend 
Fig. 3 Relationship between of Acartia (a), the C:N ratio of algae and $\Delta \delta^{15} \mathrm{~N}$ of Acartia (b), the $\mathrm{C}: \mathrm{N}$ ratio of algae and $\delta^{13} \mathrm{C}$ of Acartia (c) and the C:N ratio of algae and $\Delta \delta^{13} \mathrm{C}$ of Acartia (d). Open circles indicate mean values per treatment during the Interspecific experiments, and closed circles indicate mean values per treatment during the Limitation experiments the $\mathrm{C}: \mathrm{N}$ ratio of algae and $\delta^{15} \mathrm{~N}$
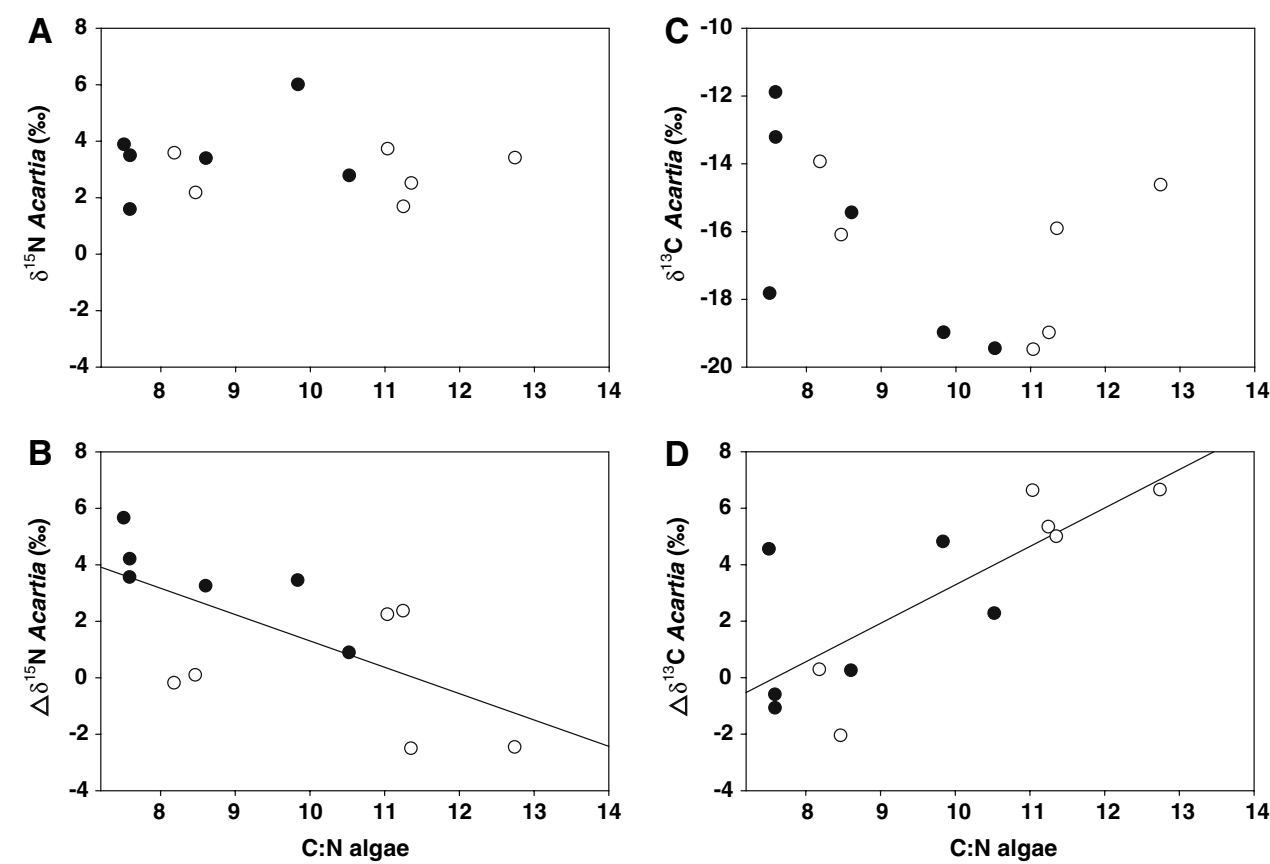

Fig. 4 Relationships between the $\delta^{15} \mathrm{~N}$ of algae and $\delta^{15} \mathrm{~N}$ of Acartia $(\mathbf{a})$, the $\delta^{15} \mathrm{~N}$ of algae and $\Delta \delta^{15} \mathrm{~N}$ of Acartia (b), the $\delta^{13} \mathrm{C}$ of algae and $\delta^{13} \mathrm{C}$ of Acartia (c) and the $\delta^{13} \mathrm{C}$ of algae and $\Delta \delta^{13} \mathrm{C}$ of Acartia (d). Open circles indicate mean values per treatment during the Interspecific experiments and closed circles indicate mean values per treatment during the Limitation experiments. Dotted lines indicate the line of equality (a, c); dashed lines indicate the postulated degree of $1.0 \%$ enrichment in $\delta^{13} \mathrm{C}$ and $3.4 \%$ enrichment in $\delta^{15} \mathrm{~N}(\mathbf{b}, \mathbf{d})$
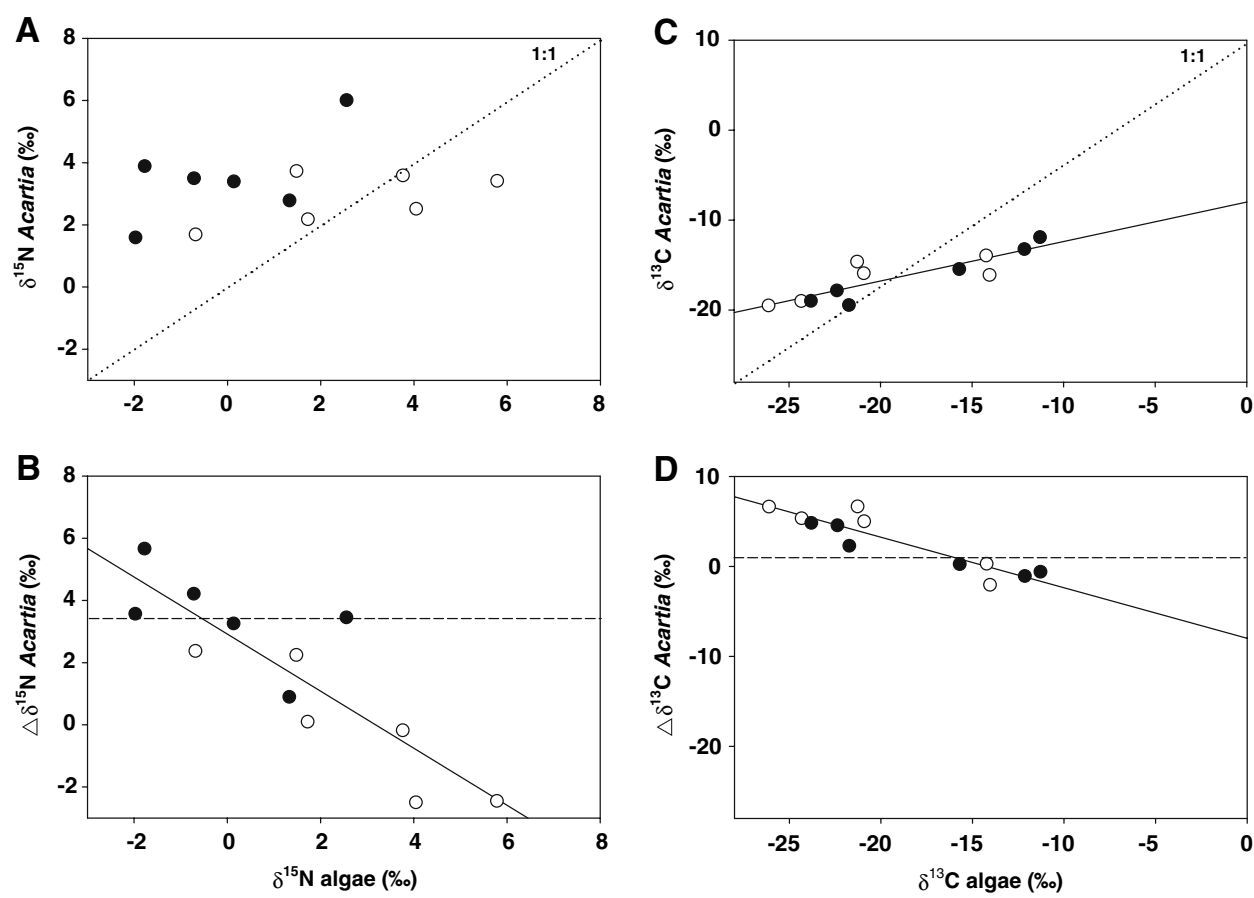

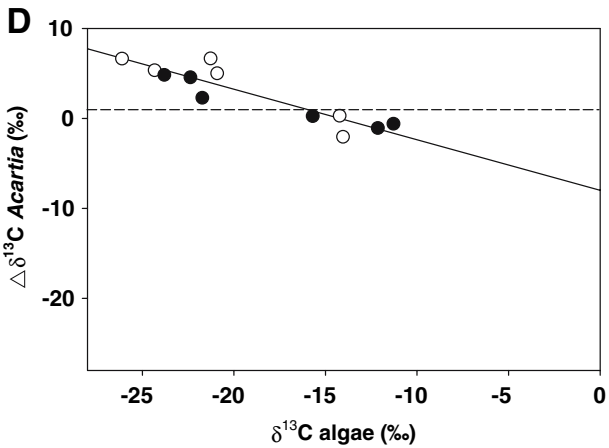

was found for $\delta^{13} \mathrm{C}$ of algae and $\Delta \delta^{13} \mathrm{C}$ of $A$. tonsa (Fig. $4 \mathrm{~d} ; r^{2}=0.83, P=0.001, b=-0.56$ ).

\section{Discussion}

Inter- and intraspecific variability as well as the impact of abiotic conditions on enrichment processes on the primary producer (Fry 1996; Burkhardt et al. 1999; Needoba et al.
2003) and the consumer level (Macko et al. 1983; Vander Zanden and Rasmussen 2001) have gained considerable importance in stable isotope ecology only recently. Therefore, Gannes et al. (1997) encouraged experimental ecologist to study enrichment processes in detail under laboratory conditions, and Vander Zanden and Rasmussen (2001) urged for a more detailed consideration of stable isotope fractionation processes when interpreting stable isotope data from the field. Our study aimed at elucidating 
such interspecific and nutrient-dependent variability of isotopic fractionation and trophic enrichment in an artificial food web by using a tri-trophic experimental approach.

\section{Nutrient-dependent variation of algae}

The Limitation experiment aimed at elucidating nutrientdependent differences in isotope fractionation of the cryptophyte $R$. salina in relation to nutrient conditions. Cryptophytes are generally considered to be more competitive than other algae when light intensities are low and nutrient concentrations high (Gervais 1997). Depending on nutrient availability of the alga, the $\delta^{15} \mathrm{~N}$ showed large nutrient-dependent variation showing high fractionation under full media and low fractionation under nutrientlimited conditions. Our results are in good correspondence with Waser et al. (1998), who reported low $\delta^{15} \mathrm{~N}$ for algae grown under $\mathrm{N}$-sufficient conditions. Nutrient-limited conditions therefore do not allow a strong discrimination against the heavier isotope ${ }^{15} \mathrm{~N}$ by microalgae, a pattern that is underpinned by our data on nitrogen-limited treatments showing high degrees of ${ }^{15} \mathrm{~N}$ enrichment, i.e., a weaker degree of fractionation compared with nutrientsufficient situations. Furthermore, the elevated $\delta^{15} \mathrm{~N}$ of $R$. salina grown under nutrient-limited conditions might not only result from isotopic fractionation during nitrogen uptake alone, but could also be related to the fact that phytoplankton excrete dissolved organic nitrogen (DON) with a low ${ }^{15} \mathrm{~N}$ content (Montoya and McCarthy 1995), thus increasing their $\delta^{15} \mathrm{~N}$.

Large variations in $\delta^{13} \mathrm{C}$ also occurred between nutrientsufficient and nutrient-depleted algae. The high $\delta^{13} \mathrm{C}$ of $R$. salina grown under nutrient-sufficient conditions corresponded well with the literature on nutrient-dependent carbon isotope fractionation (Fry and Wainright 1991; Burkhardt et al. 1999). At times when nutrients are in excess and growth rates are high, microalgae show enrichment in heavy carbon isotopes. Interestingly, when comparing the stable isotope signatures of $R$. salina during the Limitation with those during the Interspecific experiments, it became obvious that the $R$. salina cultures during the Interspecific experiments were most likely nitrogen limited. This supports our assumption that the $\delta^{13} \mathrm{C}$ depletion of $R$. salina in the Interspecific experiments results from reduced growth rates under limiting conditions.

Interspecific variation in isotope fractionation of algae

During the Interspecific experiments, the different algae showed considerable species-specific variations in $\delta^{15} \mathrm{~N}$ and $\delta^{13} \mathrm{C}$. Evidence for a taxon-specific effect was first shown by Montoya and McCarthy (1995), who reported differences in isotope fractionation between diatoms and flagellates. They found lower ${ }^{15} \mathrm{~N}$ fractionation for flagellates $(1-3 \%)$ when compared with the diatoms Skeletonema costatum and T. weissflogii (9-12\%o) and speculated that the ability of a cell to swim may enhance fractionation by preventing small-scale, local nutrient limitation. This is supported by our findings of strong ${ }^{15} \mathrm{~N}$ depletion in the flagellates $D$. salina and $R$. salina when compared with the diatom $T$. weissflogii. Not only cell motility may play an important role in determining the degree of isotope fractionation, but factors such as cell size or different metabolic demands may, also. In this context, it can also be speculated that a higher cell-surface to volume ratio of the diatom frustule might decrease the efficiency of nutrient uptake and thus might lead to lower degrees of isotope fractionation (i.e. higher enrichment levels). Taxon-specific variations in $\delta^{15} \mathrm{~N}$ have also been reported lately for lake phytoplankton by Vuorio et al. (2006). However, their study showed a strong enrichment of flagellated crysophytes (single-celled Mallomonas caudatum and colonies of Synura spp.), whereas Needoba et al. (2003) found no relationship between isotope fractionation and organism group. Thus, the ability to move seems to be only one factor influencing the degree of ${ }^{15} \mathrm{~N}$ fractionation by phytoplankton, and characteristics such as colony type, cell shape and environmental conditions (Vuorio et al. 2006) can additionally affect ${ }^{15} \mathrm{~N}$-fractionation pattern in algae cells.

In terms of ${ }^{13} \mathrm{C}$, however, both flagellates showed contrasting degrees of fractionation, with Dunaliella spp. showing a lower discrimination against heavy carbon isotopes when compared with $R$. salina. Carbon isotope fractionation during photosynthesis is known to change strongly depending on algal growth rates and the carbon sources used (Burkhardt et al. 1999). In general, cells using $\mathrm{CO}_{2}$ are expected to have lower $\delta^{13} \mathrm{C}$ values than cells using bicarbonate, and at high growth rates, a lower degree of fractionation leading to high $\delta^{13} \mathrm{C}$ is expected (Fry 1996). In our study, the different algae species were grown under equal nutrient and light conditions. As optimum growth conditions vary strongly between species, it seems likely that one algal species used in our experiment experienced better growth conditions than the other.

In addition to interspecific variability, we also found considerable batch-to-batch variability in isotope composition of algae. It can be assumed that the batch-to-batch variability was most likely related to inevitable changes in the biochemical composition of stock cultures used for the daily inoculation of the batch cultures as well as irregularities in the aeration systems, which might have led to changing $\mathrm{CO}_{2}$ supply during the growth periods. 
Trophic enrichment in the tri-tropic food chain

During the food-web experiments, the enrichment of ${ }^{15} \mathrm{~N}$ and ${ }^{13} \mathrm{C}$ per trophic level showed considerable variations from the degree of enrichment postulated in stable isotope ecology. We found no consistent enrichment patterns in trophic fractionation, as both enrichment and depletion in heavier carbon and nitrogen isotopes relative to the consumers' food sources were observed. Usually, variations in stable isotope signatures on the primary producer level are assumed as being transferred to higher trophic levels. However, the factors influencing the trophic enrichment are not sufficiently clear as yet. Recent studies reported substantial variation in consumer enrichment, thus doubting the general concept of a stepwise trophic enrichment (Oelbermann and Scheu 2002; Vanderklift and Ponsard 2003; Gaye-Siessegger et al. 2004). The authors' pointed to misleading data interpretation by neglecting nutritional, physiological and ecological background information.

One possible explanation for the deviation from the theoretical framework of trophic enrichment might be related to a lag between the isotopic turnover time of consumers (Hesslein et al. 1993; Herzka and Holt 2000), leading to disequilibrium between food and consumer. Such effects might be visible in herring larvae, which may still carry the isotopic signal of their mothers. It seems likely that the duration of the experiment was not long enough to allow the herrings to be in isotopic equilibrium with their food. This is in accordance with Schlechtriem et al. (2004), who showed that after 6 days of feeding, carp larvae contained relatively high amounts of initial material, reflecting the isotopic signature of their mothers. Interestingly, the feeding experience of herring larvae did not show a strong effect on their isotope composition, as a constant maternal signal was observed in first-feeding larvae and those who had feeding experience prior to the experiments. Only during Limitation 2 did older larvae with feeding experience show a good correspondence to the theoretical degree of $3.4 \% \Delta \delta^{15} \mathrm{~N}$ enrichment. This could be evidence for an inefficient consumption and assimilation of copepod nauplii by herring larvae in most treatments. Recent literature reported that 1 week of feeding would be an adequate period for $\delta^{13} \mathrm{C}$ and $\delta^{15} \mathrm{~N}$ of consumers converging towards equilibrium (Klein Breteler et al. 2002; Olive et al. 2003), but this clearly depends on the consumers body mass and turnover rates. Therefore, we assume that $A$. tonsa nauplii, with high turnover rates at the onset of naupliar growth and an increase in body mass of $\sim 100 \%$ from the egg to the fifth naupliar stage (Mauchline 1998), reached the isotopic equilibrium after 1 week of feeding. This assumption was based on the expectation that food sources of $A$. tonsa nauplii would show almost constant isotope composition. However, isotope composition of algae varied on a day-to-day basis, and this might be one reason for the differences between the trophic fractionation observed within our study and the theoretical framework. The pattern observed within our laboratory study provides important information on the transfer of primary producers' signals onto higher trophic levels in the field. Recent studies have pointed to large discrepancies between the isotope composition of food sources and isotope fractionation in consumers (Grey et al. 2000; Santer el al. 2006). As phytoplankton exhibit large and quick variability in their isotope composition in the field (Vuorio et al. 2006), such deviations from the expected degree of trophic enrichment in consumers could be related to considerable variability in primary producers.

A common pattern observed in stable isotope studies is that isotope signatures of consumers tend to increase in conditions of nutritional stress and starvation (Adams and Sterner 2000; Vanderklift and Ponsard 2003; Olive et al. 2003). We could not detect an increase in $\delta^{15} \mathrm{~N}$ with decreasing food quality, but we found a clear negative trend in trophic ${ }^{15} \mathrm{~N}$ enrichment $\left(\Delta \delta^{15} \mathrm{~N}\right)$ in copepods with increasing $\mathrm{C}: \mathrm{N}$ ratio (i.e. decreasing food quality for copepods). Our data are in good correspondence with earlier studies, which reported low ${ }^{15} \mathrm{~N}$ enrichment in consumers feeding on low-quality food or on diets with a low nitrogen content (Oelbermann and Scheu 2002; Haubert et al 2005). These findings might be related to homeostatic efforts of consumers, similar to the homeostasis of consumers in respect to their body nutrient composition. As under nutrient-limited conditions algae depend on the use of the entire nutrient pool and thus depend on the uptake of a high proportion of heavy isotopes, their signatures tend to increase with decreasing nutrient availability. Provided that food availability and food quality are low, similar mechanisms can be assumed for consumers. However, if food is available in excess but food quality decreases, consumers obviously tend to fractionate more strongly against heavy nitrogen isotopes in order to keep homeostasis. As shown with our data, this resulted in almost constant $\delta^{15} \mathrm{~N}$ signatures of consumers no matter how low food quality was. This pattern is contradictory to the assumption of $3.4 \%$ enrichment in $\delta^{15} \mathrm{~N}$ of consumers per trophic level that has widely been used in stable isotope ecology, although several studies stressed the flaws of the general concept, especially as far as lower trophic levels are concerned (Gannes et al. 1997; Vander Zanden and Rasmussen 2001). Today it is known that trophic fractionation of $\Delta \delta^{15} \mathrm{~N}$ is far more variable than commonly assumed and that variability is highest in detritivores and herbivores at the base of the food web (Vander Zanden and Rasmussen 2001; Vanderklift and Ponsard 2003).

Similar to diet-specific trends in $\Delta \delta^{15} \mathrm{~N}$ of nauplii, the ${ }^{13} \mathrm{C}$ enrichment per trophic level showed a highly negative 
relationship between the $\delta^{13} \mathrm{C}$ of algae and $\Delta \delta^{13} \mathrm{C}$ of $A$. tonsa. As with the $\delta^{15} \mathrm{~N}$ in copepods, the $\delta^{13} \mathrm{C}$ of the copepods did not show a reaction on food quality, thus indicating that "isotopic homeostasis" also is apparent for carbon isotopes. The results show that more isotopically enriched diets lead to a high trophic fractionation and thus a low trophic enrichment in consumers, whereas depleted diets lead to a low fractionation and consequently a high enrichment per trophic level, which by far exceeds the postulated trophic enrichment of $1.0 \%$. However, Adams and Sterner (2000) and Vanderklift and Ponsard (2003) did not report on "isotopic homeostasis", and we hypothesise that this might be related to lower food availabilities to consumers in their studies and therefore stronger constraints in terms of heavy isotope discrimination in comparison with ad libitum conditions in our experiments. However, the C:N ratio alone does not necessarily determine the quality of a food source but, rather, the entire biochemical composition. This is of considerable importance, as recent studies reported on different fractionation patterns depending on the lipid, protein and carbohydrate contents (Focken and Becker 1998; Tamelander et al. 2006), the digestibility (Aberle et al. 2005) and the microbial conditioning (Goedkoop et al. 2006) of the food items.

The aspect of "isotopic homeostasis" has not been described in the literature so far, and the regulatory mechanisms standing behind it are unknown. However, further evidence for isotopic homeostasis has been gained from a new set of experiments conducted in 2006 in which surprisingly similar results were achieved (Aberle et al., unpublished data). Future laboratory studies are needed to address the regulatory mechanisms of consumers and the potential benefit of keeping homeostasis. Furthermore, the active role of consumers in controlling fractionation processes needs to be investigated.

Overall, our results suggest that the nutritional composition of diets and the stoichiometric needs of consumers significantly affect the degree of enrichment per trophic level and that food quality aspects are of considerable importance when studying food-web relations based on stable isotope analyses in the field. More experiments under controlled laboratory conditions are needed to study heavy isotope regulatory processes and to confirm the tendency of "isotopic homeostasis" in consumers.

Acknowledgments We would like to thank Thomas Hansen for conducting the stable isotope analyses and for the fruitful discussions on stable isotope data in general. Christoph Petereit is thanked for the great collaboration and the sharing of facilities during the experiments. The helpful comments and linguistic improvements of Alexandra Kraberg are gratefully acknowledged. This study was part of the DFG-project FRISCA (AB 289/1-1) and the Helgoland Foodweb Project; we are grateful for the funding. This study complies with the current German law.

\section{References}

Aberle N, Hillebrand H, Grey J, Wiltshire KH (2005) Selectivity and competitive interactions between two benthic invertebrate grazers (Asellus aquaticus and Potamopyrgus antipodarum): an experimental study using ${ }^{13} \mathrm{C}$ - and ${ }^{15} \mathrm{~N}$-labelled diatoms. Freshw Biol 50:369-379

Adams TS, Sterner RW (2000) The effect of dietary nitrogen content on trophic level ${ }^{15} \mathrm{~N}$ enrichment. Limnol Oceanogr 3:601-607

Burkhardt S, Riebesell U, Zondervan I (1999) Effects of growth rate, $\mathrm{CO}_{2}$ concentration, and cell size on the stable carbon isotope fractionation in marine phytoplankton. Geochim Cosmochim Acta 63:3729-3741

Focken U, Becker K (1998) Metabolic fractionation of stable carbon isotopes: implications of different proximate compositions for studies of the aquatic food web using $\delta^{13} \mathrm{C}$ data. Oecologia 115:337-343

Fry B (1996) ${ }^{13} \mathrm{C} /{ }^{12} \mathrm{C}$ fractionation by marine diatoms. Mar Ecol Prog Ser 134:283-294

Fry B, Wainright SC (1991) Diatom sources of ${ }^{13}$ C-rich carbon in marine food webs. Mar Ecol Prog Ser 76:149-157

Gannes L, O'Brien D, Martinez del Rio C (1997) Stable isotopes in animal ecology: assumptions, caveats, and a call for more laboratory experiments. Ecology 78:1271-1279

Gaye-Siessegger J, Focken U, Muetzel S, Abel H, Becker K (2004) Feeding level and individual metabolic rate affect $\delta^{13} \mathrm{C}$ and $\delta^{15} \mathrm{~N}$ values in carp: implications for food web studies. Oecologia 138:175-183

Gervais F (1997) Light-dependent growth, dark survival, and glucose uptake by cryptophytes isolated from a freshwater chemocline. $\mathbf{J}$ Phycol 33:18-25

Goedkoop W, Akerblom N, Demandt MH (2006) Trophic fractionation of carbon and nitrogen stable isotopes in Chironomus riparius reared on food of aquatic and terrestrial origin. Freshw Biol 51:878-886

Gorokhova E, Hansson S (1999) An experimental study on variations in stable carbon and nitrogen isotope fractionation during growth of Mysis mixta and Neomysis integer. Can J Fish Aquat Sci 56:2203-2210

Grey J, Jones RG, Sleep D (2000) Stable isotope analysis of the origins of zooplankton carbon in lakes of differing trophic state. Oecologia 123:232-240

Guillard RL, Ryther J (1962) Studies of marine planktonic diatoms. Can J Microbiol 8:229-239

Haubert D, Langel R, Scheu S, Ruess L (2005) Effects of food quality, starvation and life stage on stable isotope fractionation in Collembola. Pedobiologia 49:229-237

Herzka S, Holt G (2000) Changes in isotope composition of red drum (Sciaenops ocellatus) larvae in response to dietary shifts: potential applications to settlement studies. Can J Fish Aquat Sci $57: 137-147$

Hesslein RH, Hallard KA, Ramlal P (1993) Replacement of sulfur, carbon and nitrogen in tissue of growing broad whitefish (Coregonus nasus) in response to a change in diet traced by delta ${ }^{34} \mathrm{~S},{ }^{13} \mathrm{C}$, and ${ }^{15} \mathrm{~N}$. Can J Fish Aquat Sci 50:2071-2076

Klein Breteler WCM, Grice K, Schouten S, Kloosterhuis HT, Damste JSS (2002) Stable carbon isotope fractionation in the marine copepod Temora longicornis: unexpectedly low ${ }^{13} \mathrm{C}$ value of faecal pellets. Mar Ecol Prog Ser 240:195-204

Macko SA, Estep MLF, Lee WY (1983) Stable hydrogen isotope analysis of food webs on laboratory and field populations of marine amphipods. J Exp Mar Biol Ecol 72:243-250

Mauchline J (1998) The biology of calanoid copepods. Academic Press, San Diego, p 710 
Minagawa M, Wada E (1984) Stepwise enrichment of ${ }^{15} \mathrm{~N}$ along food chains: further evidence and relation between $\delta^{15} \mathrm{~N}$ and animal age. Geochim Cosmochim Acta 48:1135-1140

Montoya JP, McCarthy JJ (1995) Isotopic fractionation during nitrate uptake by phytoplankton grown in continuous culture. J Plankton Res 17:439-464

Needoba J, Waser N, Harrison P, Calvert S (2003) Nitrogen isotope fractionation in 12 species of marine phytoplankton during growth on nitrate. Mar Ecol Prog Ser 255:81-91

Oelbermann K, Scheu S (2002) Stable isotope enrichment $\left(\delta^{15} \mathrm{~N}\right.$ and $\delta^{13} \mathrm{C}$ ) in a generalist predator (Pardosa lugubris, Araneae: Lycosidae): effects of prey quality. Oecologia 130: 337-344

Olive PJW, Pinnegar JK, Polunin NVC, Richards G, Welch R (2003) Isotope trophic-step fractionation: a dynamic equilibrium model. J Anim Ecol 72:608-617

Peterson B, Fry B (1987) Stable isotopes in ecosystem studies. Ann Rev Ecol Syst 18:293-320

Ponsard S, Arditi R (2000) What can stable isotopes $\left(\delta^{15} \mathrm{~N}\right.$ and $\left.\delta^{13} \mathrm{C}\right)$ tell about the food web of soil macro-invertebrates? Ecology $81: 852-864$

Ponsard S, Averbuch P (1999) Should growing and adult animals fed on the same diet show different $\delta^{15} \mathrm{~N}$ values? Rapid Commun Mass Spectr 13:1305-1310
Post D (2002) Using stable isotopes to estimate trophic position: models, methods, and assumptions. Ecology 83:703-718

Santer B, Sommerwerk N, Grey J (2006) Food niches of cyclopoid copepods in eutrophic Plußsee determined by stable isotope analysis. Arch Hydrobiol 167:301-316

Schlechtriem C, Focken U, Becker K (2004) Stable isotopes as a tool for nutrient assimilation studies in larval fish feeding on live food. Aquat Ecology 38:93-100

Tamelander T, Soreide JE, Hop H, Carroll ML (2006) Fractionation of stable isotopes in the Arctic marine copepod Calanus glacialis: effects on the isotopic composition of marine particulate organic matter. J Exp Mar Biol Ecol 333:231-240

Vander Zanden M, Rasmussen J (2001) Variation in $\delta^{15} \mathrm{~N}$ and $\delta^{13} \mathrm{C}$ trophic fractionation: implications for aquatic food web studies. Limnol Oceanogr 46:2061-2066

Vanderklift M, Ponsard S (2003) Sources of variation in consumer$\operatorname{diet} \delta^{15} \mathrm{~N}$ enrichment: a meta-analysis. Oecologia 136:169-182

Vuorio K, Meili M, Sarvala J (2006) Taxon-specific variation in the stable isotopic signatures $\left(\delta^{13} \mathrm{C}\right.$ and $\left.\delta^{15} \mathrm{~N}\right)$ of lake phytoplankton. Freshw Biol 51:807-822

Waser NAD, Harrison PJ, Nielsen B, Calvert SE, Turpin DH (1998) Nitrogen isotope fractionation during the uptake and assimilation of nitrate, nitrite, ammonium, and urea by a marine diatom. Limnol Oceanogr 43:215-224 